\title{
Are Adults Aware of the Existence of Rheumatic Disease in Childhood?
}

\author{
Erişkinler Çocuk Romatizma Hastalıklarının Farkında mı? \\ Salih KAVUKÇU, Mehmet TÜRKMEN, Alper SOYLU \\ Department of Pediatrics, Medical Faculty of Dokuz Eylül University, Izmir, Turkey
}

Some diseases are thought to be only for the adults or the elderly and are not normally seen in the pediatric age group. For example, hypertension is usually known as an adulthood disease, and most parents are astonished when we try to measure the blood pressure of their children during routine pediatric examination.

Rheumatic diseases in children are not well-known by parents. If families are not aware of the symptoms of childhood rheumatic diseases, this may lead to a delay in presenting to a physician which could delay the diagnosis. ${ }^{[1]}$ The reason for this erroneous perception may be the low prevalence of rheumatic diseases in the pediatric age group which leads to parents overlooking the disease. ${ }^{[2-4]}$

We aimed to find out how much adults knew about childhood rheumatic diseases.

The questionnaire in below was requested to be filled in by the adults who applied to different outpatient clinics, excluding the pediatric department, in our hospital. Statistical analyses were carried out by Statistical Package for the Social Sciences (SPSS, Inc., Illinois USA) version 15.0 for Windows using the chi-square test A $p$ value of $<0.05$ was considered significant.

Questionnaire for adults about childhood rheumatic diseases

Q1. Name (optional)

Q2. Age
Q3. Gender

1. Male

2. Female

Q4. Educational status

1. Illiterate

2. Primary school

3. Middle school

4. High school

5. College

6. Graduate

Q5. Profession

1. Housewife

2. Searching for a job

3. Other

Q6. Which outpatient clinic do you most often visit?

Q7. Do you have children?

1. Yes (Please indicate how many)

2. No

B1. Can you name any childhood rheumatic diseases?

1. Yes

2. No

B2. Which organs are affected in children with rheumatic diseases?

1. Bone/joint/muscle

2. Eyes

3. Brain

4. Kidneys

5. Stomach/intestines

6. Heart

7. Lungs

8. Skin

Received: June 24, 2011 Accepted: November 17, 2011

Correspondence: Salih Kavukçu, M.D. Dokuz Eylül Üniversitesi Tıp Fakültesi Çocuk Sağlı̆ı̆ ve Hastalıkları Anabilim Dalı, 35210 Alsancak, İzmir, Turkey. Tel: +90 232 - 4123650 e-mail: s.kavukcu@deu.edu.tr

(02012 Turkish League Against Rheumatism. All rights reserved. 
B3. Which complaints often occur in childhood rheumatic diseases?
1. Fever
2. Weakness, fatigue
3. Shortness of breath
4. Abdominal pain
5. Joint pain/swelling
6. Inability to walk/limping
7. Chest pain
8. Bloody stool
9. Bloody urine
10. Swelling of the face and eyelids
11. Skin rush
12. Blurred vision, loss of vision
13. Having a fit
14. High blood pressure
15. Headache
16. Mouth sores
17. Hair loss

B4. Can you name any consequences of childhood rheumatic diseases? If yes, please identify which ones.

1. Claudication/disability

2. Kidney failure

3. Heart disease

4. Blindness

5. Stroke

6. Epilepsy

7. Short stature/growth retardation

B5. Where did you learn about this information?

The number of people who responded to the survey was 494 (mean age $42.2 \pm 15.6$ years, range 18 to 85 years). There were 216 males $(43.7 \%$, mean age $43.0 \pm 16.5$ years) and 278 females $(56.3 \%$, mean age $41.5 \pm 14.8$ years). Participants who answered, "yes" to the question "Can you name any childhood rheumatic diseases?" were considered to be informed (78.5\%) while the rest were considered to be uninformed (21.5\%). Participants were more informed if they were female $(84.5 \%$ in females versus $70.8 \%$ in males, $\mathrm{p}<0.001)$, graduates/postgraduates $(88.4 \%$ in graduates/postgraduates versus $73.6 \%$ in the rest, $\mathrm{p}<0.001$ ), employed ( $81.0 \%$ in employed versus $46.9 \%$ in unemployed, $\mathrm{p}<0.001)$, or had children $(81.1 \%$ in those with children versus $71.3 \%$ in those without children). However, education level had no significant impact on awareness about these diseases in females $(92.1 \%$ in graduates/postgraduates versus $81.7 \%$ in the rest, $\mathrm{p}=0.058)$. Informed respondents were highest among outpatients of the thoracic medicine department and lowest among outpatients of the gastroenterology department. The difference between these two groups was significant ( $\mathrm{p}=0.011$ ).

Participants reported the rate of organ involvement in childhood rheumatic diseases as follows: bone/joint/muscle $94.6 \%$, heart $48.7 \%$, kidney $31.7 \%$, eye $23.5 \%$, skin $19.8 \%$, brain $17.8 \%$, lung $14.7 \%$, and gastrointestinal system $12.9 \%$. The rate of complaints in children with rheumatic diseases according to participants was as follows: joint pain and swelling $83.5 \%$, weakness/fatigue $74.0 \%$, inability to walk/limping $64.2 \%$, fever $45.6 \%$, headache $32.7 \%$, swelling of the face and eyelids $26.5 \%$, skin rush $23.7 \%$, shortness of breath $23.5 \%$, chest pain $19.6 \%$, abdominal pain $17.3 \%$, loss of vision/blurred vision $15.2 \%$, having a fit $15.7 \%$, hypertension $13.9 \%$, hair loss $11.3 \%$, mouth sores $10.1 \%$, bloody urine $6.2 \%$, and bloody stool $4.4 \%$. Participants denoted the specific consequences of childhood rheumatic diseases as claudication/ disability $54.1 \%$, short stature/growth retardation $45.3 \%$, heart disease $26.9 \%$, stroke $16.1 \%$, renal failure $14.8 \%$, blindness $6.5 \%$, and epilepsy $4.9 \%$.

The participants reported their sources of information as personal contact with friends, neighbors, etc. $66.8 \%$, television $11.2 \%$, internet $7.8 \%$, newspaper/ magazine $7.3 \%$, medical staff $7.0 \%$, having a child with rheumatic disease $3.9 \%$, and having a rheumatic disease themselves $3.1 \%$.

The awareness of adults regarding childhood diseases, is important in terms of preventive medicine in pediatrics. The diseases within the scope of pediatric rheumatology and their symptoms are often unknown by adults. In this paper, adult awareness of childhood rheumatic diseases was studied, and more than $20 \%$ of the 494 respondents were unaware of them. Although the level of education and awareness increased equally, this was not true for the women. Approximately $80 \%$ of the women who are housewives were aware of childhood rheumatic diseases. The participants who had children were significantly more aware of childhood rheumatic diseases than those who did not have children. Although pediatric rheumatology is related to orthopedics, adult immunology, and rheumatology, the rates of awareness of childhood rheumatic diseases among participants from these outpatient clinics were not different from the participants in other outpatient clinics. While involvement of the musculoskeletal system was highly referenced by the participants, their knowledge about the involvement of other 
systems was lower. The source of information for most of the participants was non-experts (friends, neighbors, relatives, etc.). This implies there is insufficient formal training public in the area of pediatric rheumatology. ${ }^{[2-4]}$

In conclusion, more than $20 \%$ of the adult population in the third biggest city in Turkey were not aware of childhood rheumatic diseases. The awareness increases parallel to educational level (at least in males). However, most of those who heard about childhood rheumatism obtained this knowledge via informal sources, such as from their neighbors. Although this study was performed on a limited sample of the population, the results indicate that formal education of the community about childhood rheumatic diseases should be undertaken in order for there to be timely presentation and effective treatment for children with these diseases.

\section{Acknowledgment}

This work is planned as a "Student Working Module" and prepared with their contributions

\section{Declaration of conflicting interests}

The authors declared no conflicts of interest with respect to the authorship and/or publication of this article.

\section{Funding}

The authors received no financial support for the research and/or authorship of this article.

\section{REFERENCES}

1. Arkachaisri T. Pediatric rheumatology in Southeast Asia: insights from the Singapore experience. Curr Rheumatol Rep 2011;13:117-22.

2. Essawy MA, Bahgat ZS, Kassem HA. Health-related quality of life of school- age children with rheumatic Fever. J Egypt Public Health Assoc 2010;85:205-22.

3. Thon A, Ullrich G. Information needs in parents of children with a rheumatic disease. Child Care Health Dev 2009;35:41-7.

4. Al-Eid WM, Madi SM, Bahabri SA, Al-Mayouf SM. Evaluation of parental knowledge of Pediatric Rheumatic Diseases. Saudi Med J 2001;22:531-6. 